\title{
Pregnancy in past or present lupus nephritis: a study of 32 pregnancies from a single centre
}

\author{
D Lê Thi Huong, B Wechsler, D Vauthier-Brouzes, H Beaufils, G Lefebvre, J-C Piette
}

\begin{abstract}
Objective-To study maternal and fetal outcome in women with past or present histologically proven systemic lupus erythematosus (SLE) nephritis.

Method-Retrospective study of 32 pregnancies in 22 women with past or present histologically proven SLE nephritis in a single French centre.
\end{abstract}

Results-Pregnancy (25 planned and 7 not planned) occurred in a mean (SD) of 8 (5) years after SLE diagnosis and 6 (4) years after renal disease onset. Seven occurred in women with antiphospholipid syndrome. At pregnancy onset, all but one woman had creatininaemia below 100 $\mu \mathrm{mol} / 1$, five had proteinuria $>0.5 \mathrm{~g} / \mathrm{day}$, none had hypertension. Twelve pregnancies occurred in women previously treated with immunosuppressant drugs. Treatment comprised prednisone $(n=31)$, hydroxychloroquine $(n=11)$, aspirin $(n=22)$, heparin $(n=12)$, and azathioprine in one patient with steroid resistant nephrotic syndrome disclosing SLE. No therapeutic abortion was done. During pregnancy or the postpartum period, or both, proteinuria $>0.5 \mathrm{~g} /$ day occurred in 10 women (five related to pre-eclampsia, four to renal flare, one to stable nephrotic syndrome). One flare consisted of mild arthralgias. Pregnancy outcome comprised one fetomaternal death in SLE disclosed by pregnancy, five embryonic losses, two fetal deaths, and 18 premature (one neonatal death) and six full term births. No criterion appeared to influence fetal survival significantly. At long term, one patient died during an SLE flare, three women had renal relapses. At the last visit, all had creatininaemia below $100 \mu \mathrm{mol} / 1$ except one woman with creatinine level 115 $\mu \mathrm{mol} / 1$, nine had proteinuria $>0.5 \mathrm{~g} / \mathrm{day}$, and one was treated for hypertension.

Conclusion-Pregnancy need not be discouraged in women with a history of SLE nephritis with normal or mildly impaired renal function. Deterioration of renal function rarely occurs. However, these pregnancies are at high risk of preeclampsia and prematurity. (Ann Rheum Dis 2001;60:599-604)

Systemic lupus erythematosus (SLE) affects, particularly, women of childbearing age. Global SLE survival improvement due to better therapeutic management would lead to authorisation of pregnancy in an increased number of women. However, most studies analysing the relations between SLE and pregnancy found high fetal and maternal risksnotably, when pregnancy occurs in active SLE. ${ }^{1}$ In our 1987-91 French prospective study, SLE exacerbation was seen in $60 \%$ of the pregnancies and resulted in maternal death in $1.9 \%$ of the cases. Sixty three per cent of the newborn infants were premature, $29 \%$ growth retarded, and 5\% died. ${ }^{2}$ Between 1982 and 1995 we prospectively "planned" 62 pregnancies in 38 women with SLE followed up in our department. Flares occurred in $27 \%$ of the cases. No child or mother died. After exclusion of early spontaneous and induced abortions, the live birth rate was $96 \%$, which is close to that of the general French population. ${ }^{3}$

Nephritis is known to be one of the most serious complications of SLE and a strong predictor of poor outcome. However, its influence on mortality has decreased in recent studies, ${ }^{45}$ and a growing number of women with nephritis in the past wish to be pregnant. Our study aimed at analysing fetal and maternal courses and identifying risk factors in women with previous SLE nephritis in a tertiary referral centre. Fourteen planned and four non-planned pregnancies were included in previous global reports on SLE pregnancies. ${ }^{2}{ }^{3}$

\section{Patients and methods}

PATIENTS

Between 1982 and 1999 we followed up 32 pregnancies in 22 women with histologically proven SLE nephritis. Nephritis occurring after delivery was not taken into account. Thirteen women had one pregnancy, eight had two successive pregnancies, and one women had three. All patients fulfilled the 1997 American College of Rheumatology criteria for SLE. ${ }^{6}$ Antiphospholipid syndrome (APS) was diagnosed according to the recent criteria. ${ }^{7}$ Histological patterns of SLE nephritis were assessed by the 1995 WHO classification. ${ }^{8}$

\section{DEFINITIONS}

We used the following definitions:

- Embryonic loss: according to Branch's definition used in APS, spontaneous termination of pregnancy before 10 weeks' gestation $^{9}$

- Fetal death: death of a fetus shown to be alive at or beyond 10 weeks' gestation

- Premature birth: termination of pregnancy with a live birth between weeks 21 and 37

- Full term birth: termination of pregnancy with a live birth between 38 and 40 weeks

- Intrauterine growth retardation: birth weight below the 10th centile for the stated gestation

- Hypertension: diastolic pressure above 90 $\mathrm{mm} \mathrm{Hg}$ 
Table 1 Outcome in 22 prior pregnancies in 11 women and 32 treated pregnancies in 22 women with past or present lupus nephritis. Values are shown as No (\%)

\begin{tabular}{|c|c|c|c|c|c|}
\hline & $\begin{array}{l}\text { Induced abortions } \\
\text { for unwanted } \\
\text { pregnancy }\end{array}$ & $\begin{array}{l}\text { Therapeutic } \\
\text { abortions }\end{array}$ & Embryonic losses & $\begin{array}{l}\text { Fetal deaths or } \\
\text { stillbirths }\end{array}$ & Live births \\
\hline Previous pregnancies $(n=22)$ & $2(9)$ & $5(23)$ & $5(23)$ & $3(13)$ & $7(32)$ \\
\hline \multicolumn{6}{|l|}{ Known SLE with } \\
\hline Planned pregnancies $(n=25)$ & 0 & 0 & $4(16)$ & $1(4)$ & $20(80)$ \\
\hline Non-planned pregnancies, $(n=6)$ & 0 & 0 & $1(17)$ & $2^{\star}(33)$ & $3(50)$ \\
\hline SLE onset during pregnancy $(n=1)$ & 0 & 0 & 0 & $1 \dagger$ & 0 \\
\hline \multicolumn{6}{|l|}{ Known SLE } \\
\hline Active at pregnancy onset $(n=3)$ & 0 & 0 & 0 & $1^{\star}(33)$ & $2(67)$ \\
\hline Inactive at pregnancy onset $(n=28)$ & 0 & 0 & $5(18)$ & $2(7)$ & $21(75)$ \\
\hline \multicolumn{6}{|l|}{ Known SLE } \\
\hline Active during pregnancy $(n=3)$ & 0 & 0 & 0 & 0 & $3(100)$ \\
\hline Inactive during pregnancy $(n=28)$ & 0 & 0 & $5(18)$ & $3^{\star}(11)$ & $20(71)$ \\
\hline
\end{tabular}

*One neonatal death.

†One fetomaternal death.

- Pre-eclampsia: hypertension complicated with proteinuria or oedema, or both

- Eclampsia: pre-eclampsia complicated with seizures or fitting

- Adverse pregnancy outcome: at least three successive embryonic losses, therapeutic abortion, fetal or neonatal death.

STATISTICAL METHODS

Statistical analyses were carried out with a two sided Fisher's exact test.

\section{Results}

AGE, FERTILITY, CHARACTERISTICS OF SLE

NEPHRITIS

Mean (SD) age at first pregnancy was 30 (4)

years (range 18-35). One woman with sterility related to endometriosis had two consecutive induced pregnancies. Induction of ovulation was carried out with aspirin, hydroxychloroquine, and $15 \mathrm{mg}$ prednisone daily. The first pregnancy was twin and occurred after the second cycle of in vitro fertilisation and embryo transfer. It spontaneously reduced to a singleton. The second pregnancy, occurring after in vitro fertilisation of a cryopreserved embryo, ended in embryonic loss. The other pregnancies were spontaneous.

At entry to the study, 11 women were nulliparous and 11 multiparous with 22 previous pregnancies. One multiparous women had had one previous fetal death related to APS. Five women had had seven normal pregnancies before SLE onset. Two women had a history of neonatal death. The other pregnancies led to embryonic losses $(n=5)$, induced abortions for unwanted pregnancies $(n=2)$ or for medical indication $(\mathrm{n}=5)$. Hence, fetal survival after exclusion of induced abortions was 7/15 $(47 \%)$, but it was nil if only pregnancies occurring after SLE onset were taken into account (table 1).

Mean (SD) time between SLE diagnosis and pregnancy was 8 (5) years (maximum 18), and between renal disease onset and pregnancy was 6 (4) years (maximum 18). At pregnancy onset, SLE was known to be present in all patients except one, in whom SLE was diagnosed during the second trimester. The former patients had been previously treated with high dose prednisone, together with immunosuppressant drugs in eight women who had 12 pregnancies: oral cyclophosphamide during one year $(n=1)$, azathioprine $(n=2)$, and intravenous cyclophosphamide $(n=9)$. Six pregnancies occurred in women treated with eight or fewer cyclophosphamide pulses, three in women treated with 11 pulses or more (maximum 18). Mean age at cyclophosphamide initiation was 25 (5) years (range 18-32). Eighteen pregnancies occurred in women previously treated with prednisone without immunosuppressant drugs. Two women with no previous renal disease developed nephrotic syndrome during pregnancy. One had known SLE, and postpartum renal biopsy disclosed diffuse proliferative glomerulonephritis. Pregnancy showed SLE in the other woman. Treatment consisted of high dose prednisone together with azathioprine. She died at 25 weeks from bacillus septicaemia. A postmortem examination disclosed diffuse proliferative glomerulonephritis.

Before pregnancy, with the exception of one woman with a creatine level of $107 \mu \mathrm{mol} / \mathrm{l}$, all women had creatininaemia below $100 \mu \mathrm{mol} / 1$, but the serum creatinine level had reached 100 $\mu \mathrm{mol} / 1$ or more during previous renal flares in eight cases. Five women had proteinuria higher than $0.5 \mathrm{~g} /$ day, of whom one was nephrotic. None was treated for hypertension. Seventeen pregnancies occurred in women with antiphospholipid antibodies (aPL): anticardiolipin antibodies alone in 14 cases, lupus anticoagulant in six cases, of whom seven had APS. Eight pregnancies occurred in women with anti-SSA antibodies, associated with anti-SSB in two. None had a history of congenital atrioventricular block and none had received treatment to prevent it.

NON-PLANNED PREGNANCIES

In addition to the case of SLE discovered during pregnancy, six other pregnancies were not planned. Three pregnancies occurred in women with active SLE: a proliferative glomerulonephritis was discovered a few months before pregnancy in two cases. A relapse with autoimmune haemolytic anaemia and nephrotic syndrome related to membranous glomerulonephritis appeared two months before pregnancy in the last case. Three pregnancies occurred in women with inactive SLE. One woman became pregnant a few 
Table 2 Outcome of pregnancies in women with SLE nephritis that occurred before, during pregnancy, or in the postpartum period

\begin{tabular}{|c|c|c|c|c|c|c|}
\hline Authors Date Reference & $\begin{array}{l}\text { Number of } \\
\text { pregnancies/ } \\
\text { women }\end{array}$ & $\begin{array}{l}\text { Spontaneous } \\
\text { abortion } \\
\text { No (\%) }\end{array}$ & $\begin{array}{l}\text { Therapeutic } \\
\text { abortion } \\
\text { No (\%) }\end{array}$ & $\begin{array}{l}\text { Stillbirth or } \\
\text { neonatal death } \\
\text { No (\%) }\end{array}$ & $\begin{array}{l}\text { Premature birth } \\
\text { No }(\%)\end{array}$ & $\begin{array}{l}\text { Full term } \\
\text { birth } \\
\text { No (\%) }\end{array}$ \\
\hline Hayslett and Lynn 1980 (20) & $65 / 47\left(56^{\star}\right)$ & $9(16)$ & $10(18)$ & $2(4)$ & $1(2)$ & $34(61)$ \\
\hline \multirow[t]{2}{*}{ Jungers et al 1982 (22) } & $104 / 36$ & & & & & \\
\hline & $35^{\star}$ & $5(14)$ & $5(14)$ & $1(3)$ & $4(11)$ & $20(57)$ \\
\hline Imbasciati et al 1984 (21) & $26 / 19$ & $4(15)$ & $2(8)$ & $5(19)$ & $9(35)$ & $6(23)$ \\
\hline Oviasu et al 1991 (18) & $53 / 25$ & $8(15)$ & $6(11)$ & $1(2)$ & $10(19)$ & $28(53)$ \\
\hline Pachkam et al 1992 (28) & $64 \uparrow / 41$ & $5(8)$ & $5(8)$ & $12(18)$ & $19(29)$ & $24(37)$ \\
\hline Julkunen et al 1993 (19) & $26 / 16$ & $1(4)$ & $2(8)$ & $1(4)$ & $6(23)$ & $16(62)$ \\
\hline Our series & $32 / 22$ & $7(22)$ & 0 & $2(6)$ & $17(53)$ & $6(19)$ \\
\hline
\end{tabular}

*Pregnancies occurring after or at SLE onset.

†One twin pregnancy.

weeks after her eighth monthly cyclophosphamide pulse and did not want an abortion. In the second case, nephrotic syndrome appeared while receiving $15 \mathrm{mg}$ prednisone daily. Postpartum renal biopsy disclosed diffuse proliferative glomerulonephritis. In these cases, cyclophosphamide was stopped, the prednisone dose was increased to a mean of 25 $\mathrm{mg}$ /day (range 20-75). Low molecular weight heparin was started in two cases of nephrotic syndrome, together with aspirin in one case. Aspirin alone was prescribed in one case. Hydroxychloroquine was withdrawn in one case seen before 1995, started in one more recent pregnancy, and maintained in a third case.

In the last unplanned pregnancy in a woman with previous mesangial glomerulonephritis, diffuse proliferative glomerulonephritis occurred while receiving hydroxychloroquine two months after embryonic loss.

\section{PLANNED PREGNANCIES}

Twenty five pregnancies were planned as previously reported. ${ }^{3}$ Pregnancy was contraindicated when serum creatinine was above 130 $\mu \mathrm{mol} / 1$. Prior renal biopsies had shown mesangial glomerulonephritis $(n=2)$, focal proliferative $(n=4)$, diffuse proliferative $(n=10)$, pure membranous glomerulonephritis $(n=8)$, and focal segmental glomerulosclerosis $(n=1)$. The last of these was considered to be specific to SLE because of a positive immunofluorescence study and corticosensitivity. Before pregnancy, three women were treated with hydroxychloroquine alone, 22 with prednisone (mean (SD) dose 10 (4.7) $\mathrm{mg} /$ day; range 5-20) alone or associated with antimalarial drugs in 10 cases. Upon pregnancy diagnosis, treatment with prednisone was started or its dose increased (mean 6 (10) $\mathrm{mg} /$ day). No treatment with immunosuppressant drugs was started. Hydroxychloroquine was withdrawn in two cases before 1995; after 1995 it was maintained in 11 cases. Aspirin was prescribed in 19 cases because of positive aPL or for eclampsia prevention, or both. Low molecular weight heparin was started in nine cases owing to a history of vascular thrombosis $(n=5)$ or miscarriages under aspirin treatment $(n=4)$, or both; it was associated with aspirin in nine cases. No therapeutic abortion was indicated.
FETAL OUTCOME

Table 2 summarises the outcome of the 32 pregnancies. One feto-maternal death occurred. Twenty eight babies (two pairs of twins) were born: 15 boys and 13 girls.

The outcome of six non-planned pregnancies was one embryonic loss, one fetal death, and four premature births (one twin pregnancy). Mean pregnancy duration was 32 (4) weeks (range 27-36). Average birth weight was 2200 (836) g (range 1250-2800). Caesarean section was indicated in one twin pregnancy. In one woman, ovarian cyst torsion was complicated by premature birth with neonatal death. One premature child remitted from perfringens neonatal infection. Pre-eclampsia occurred in a woman with APS followed up in 1982 and treated with prednisone without heparin or aspirin, leading to fetal death at six months.

The outcome of the 25 planned pregnancies was six full term births, 14 premature births (one twin), four embryonic losses, and one fetal death at 12 weeks' gestation in women with no clinical signs of SLE activity and no APS. Mean pregnancy duration was 33 (6) weeks (range 27-39) and average birth weight was 2722 (646) g (range 1000-3600). Caesarean section was carried out in six cases (five premature and one full term delivery). This was indicated by fetal distress in four cases, herpes zoster recurrence in one case, and ventricular shunt in one case. Five premature infants were growth retarded, and one had transient respiratory distress. The live birth rate was $24 / 32(75 \%)$. Neonatal lupus, adrenal insufficiency, or congenital malformation were not seen.

INDICATORS OF FETAL PROGNOSIS

We analysed the following indicators for live birth rate: planned pregnancy, SLE activity, serum creatinine, and proteinuria at pregnancy onset and during pregnancy, hypertension during pregnancy, presence of proliferative lesions on renal biopsy, presence of APS, aPL, anti-SSA antibodies, complement level at pregnancy onset, maximum corticosteroid dose during pregnancy, and use of heparin during pregnancy. No criterion reached statistical significance.

RENAL AND MATERNAL OUTCOME

During pregnancy, proteinuria appeared in five women, in addition to the five women with known proteinuria. Proteinuria was related to 
pre-eclampsia in five pregnancies, associated with features of HELLP syndrome (haemolysis, elevated liver enzymes, low platelets) in one. Sudden hyperuricaemia and an abnormal obstetric ultrasound Doppler examination (notched uterine artery or raised resistance in umbilical artery, or both) were the initial signs. Serum complement was normal in three cases, decreased in two. DNA antibodies were negative in all cases. Three of these five pregnancies were planned. Three of the five occurred in APS with a history of vascular thrombosis. During pregnancy, treatment consisted of prednisone (mean maximum daily dose 27 (27) mg; range 10-75), associated with aspirin plus heparin $(n=1)$, aspirin alone $(n=2)$, or heparin alone $(n=1)$, and one woman followed up in 1982 received neither heparin nor aspirin. Previous renal biopsy had disclosed diffuse proliferative glomerulonephritis in one case, focal proliferative glomerulonephritis in another, membranous glomerulonephritis in two, and focal glomerulosclerosis in the last. Fetal distress accompanied preeclampsia in four cases, leading to fetal death in one case. Caesarean section was indicated in three cases at 27-35 weeks and vaginal delivery was induced in one case at 31 weeks.

Nephrotic syndrome due to membranous glomerulonephritis remained stable during pregnancy and the postpartum period in one woman. Proteinuria was related to renal flare in four cases which occurred during the late second or the third trimester. SLE was diagnosed during one pregnancy. Two pregnancies were not planned pregnancies and two were planned. Two women had a history of glomerulonephritis, proliferative diffuse in one, mesangial in the other. Serum complement levels were low in all cases and DNA antibodies positive in three of four cases. This was disclosed by nephrotic syndrome in two cases. Hypertension was absent, but renal insufficiency appeared in one case (maximum serum creatinine $160 \mu \mathrm{mol} / \mathrm{l})$. Histological examination disclosed diffuse proliferative glomerulonephritis in three cases (one postmortem, one postpartum, and one postabortum renal biopsy). The third woman with previous diffuse proliferative glomerulonephritis did not have a renal biopsy because the renal abnormalities remitted in the postpartum period.

Another SLE flare consisted of mild arthralgia not needing any treatment modification.

Two women with previous APS developed thromboembolic events: iliofemoral thrombophlebitis in one non-treated case in 1982, ovarian cyst torsion complicated by postoophorectomy inferior vena caval thrombosis and pulmonary embolism, despite calcium heparin, in another case. The other maternal complications, present in three women, consisted of postpartum wall haematoma in a patient receiving both heparin and aspirin treatment, postpartum clostridium septicaemia, genital perfringens infection complicated by neonatal infection, and herpes zoster recurrence at delivery. No patient had an osteoporosis related fracture.
At long term follow up, one other patient died during an SLE flare when her child was four years old. Renal relapse occurred in three women in the subsequent one to two years: one women relapsed from diffuse proliferative glomerulonephritis, another woman with previous mesangial glomerulonephritis developed diffuse proliferative glomerulonephritis, and the last woman relapsed from focal glomerulosclerosis. All were treated with high dose prednisone and monthly cyclophosphamide pulses. In the other patients, SLE is fairly controlled by maintenance treatment with low dose prednisone or antimalarial drugs, or both. At the last visit, all women had creatininaemia below $120 \mu \mathrm{mol} / 1$ and one was treated for severe hypertension.

\section{Discussion}

MATERNAL PROGNOSIS

Studies on pregnancy outcome in women with past or current SLE nephritis are scarce. This may be explained, in part, by $(a)$ the reduced fertility associated with long term cyclophosphamide $^{10}$ or impaired renal function, ${ }^{11}$ or both, and (b) the classical assumption that pregnancy should be discouraged in women with a history of lupus nephritis. Of note, in our series, 13 pregnancies occurred in women previously treated with cyclophosphamide. Several studies have shown that the incidence of ovarian failure paralleled the increased age at cyclophosphamide initiation and cumulative dosage. ${ }^{10}$

In our study all the women had nearly normal renal function with pre-pregnancy serum creatinine below $100 \mu \mathrm{mol} / 1$ (that is, 0.8 $\mathrm{mg} / \mathrm{dl}$ ). At UCLA, ${ }^{11} 38$ pregnancies in 26 SLE women with normal or minimally impaired prepartum renal function (serum creatinine $<90 \mu \mathrm{mol} / 1(<1 \mathrm{mg} / \mathrm{dl})$, clearance $>80 \mu \mathrm{ml} / \mathrm{min}$, proteinuria $<1 \mathrm{~g} /$ day) ended in 10 abortions, whereas 14 pregnancies in 13 women with "mild" impairment (clearance $50-80 \mathrm{ml} / \mathrm{min}$, proteinuria 1-3 g/day) ended in five abortions. Hence, the rate of successful pregnancy was 1.08 per woman with normal or minimally impaired renal function and decreased to 0.69 in case of mild renal impairment.

We noted that SLE flared up in five cases. However, the more severe aspect consisting of nephrotic syndrome was seen only in the nonplanned pregnancies. Hence, the flare rate of SLE seems to be lower in a series including only women with SLE nephritis than in women with all patterns of SLE. In prospective studies conducted in referral centres, ${ }^{313-17}$ the SLE flare rate associated with pregnancy was around $60 \%$. In a nephrological series including only women with SLE nephritis diagnosed before pregnancy, flare rates of $0 \%$ and $9 \%$ were found in the most recent studies, ${ }^{18}{ }^{19}$ probably because most pregnancies had begun when SLE was in remission. On the contrary, in the older studies including women with SLE nephritis diagnosed during pregnancy, higher flare rates, up to $81 \%,{ }^{20-22}$ were seen (table 3 ).

When renal anomaly appears during pregnancy in SLE, the crucial question remains the 
Table 3 SLE and renal course in pregnancies with SLE nephritis

\begin{tabular}{|c|c|c|c|c|c|c|c|}
\hline \multirow{2}{*}{$\begin{array}{l}\text { Authors Date Reference } \\
\text { Hayslett and Lynn } 1980 \text { (20) }\end{array}$} & \multirow{2}{*}{$\begin{array}{l}\begin{array}{l}\text { Onset renal disease/ } \\
\text { pregnancy }\end{array} \\
56 \text { Before } \\
6 \text { During } \\
3 \text { After }\end{array}$} & \multicolumn{2}{|c|}{$\begin{array}{l}\text { Histological pattern first } \\
\text { renal biopsy }\end{array}$} & \multirow{2}{*}{$\begin{array}{l}\text { SLE flare No(\%) } \\
\mathrm{R} \dagger=10 / 31(32) \\
\mathrm{A} \dagger=22 / 25(88) \\
\mathrm{D} \dagger=9(100)\end{array}$} & \multirow{2}{*}{$\begin{array}{l}\begin{array}{l}\text { Renal flare No } \\
(\%)\end{array} \\
\mathrm{R}=9(29) \\
\mathrm{A}=15(60) \\
\mathrm{D}=6(67)\end{array}$} & \multirow{2}{*}{$\begin{array}{l}\begin{array}{l}\text { Worsening } \\
\text { renal function } \\
\text { No }(\%)\end{array} \\
\mathrm{R}=3(10) \\
\mathrm{A}=7(28) \\
1 \text { Dialysis } \\
\mathrm{D}=3(33)\end{array}$} & \multirow{2}{*}{$\begin{array}{l}\begin{array}{l}\text { Death No } \\
(\%)\end{array} \\
\mathrm{R}=0 \\
\mathrm{~A}=2(8) \\
\mathrm{D}=1(11)\end{array}$} \\
\hline & & $\begin{array}{l}\text { I } \\
\text { II } \\
\text { III } \\
\mathrm{ND}^{\star}\end{array}$ & $\begin{array}{l}8 \\
7 \\
36 \\
6\end{array}$ & & & & \\
\hline Jungers et al 1982 (22) & $\begin{array}{l}26 \text { Before } \\
4 \text { During } \\
5 \text { After }\end{array}$ & $\begin{array}{l}\text { II } \\
\text { III } \\
\text { IV } \\
\text { V } \\
\mathrm{ND}^{\star}\end{array}$ & $\begin{array}{l}5 \\
8 \\
6 \\
2 \\
5\end{array}$ & $27(77)$ & $13(37)$ & $\begin{array}{l}5(14) \\
2 \text { Dialysis }\end{array}$ & 0 \\
\hline Imbasciati et al 1984 (21) & $\begin{array}{l}6 \text { Before } \\
18 \text { During } \\
2 \text { After }\end{array}$ & $\begin{array}{l}\text { II } \\
\text { III } \\
\text { IV } \\
\text { V }\end{array}$ & $\begin{array}{l}3 \\
5 \\
6 \\
5\end{array}$ & $21(81)$ & $18(69)$ & $\begin{array}{l}7 \text { (27) } \\
2 \text { Permanent } \\
1 \text { Dialysis }\end{array}$ & $2(10.5)$ \\
\hline Oviasu et al 1991 (18) & 53 Before & $\begin{array}{l}\text { II } \\
\text { III } \\
\text { IV } \\
\text { V } \\
\mathrm{ND}^{\star}\end{array}$ & $\begin{array}{l}5 \\
10 \\
25 \\
10 \\
3\end{array}$ & 0 & $6(11)$ & $\begin{array}{l}6(11) \\
\text { Transient }\end{array}$ & 0 \\
\hline Pachkam et al 1992 (28) & $\begin{array}{l}46 \text { Before } \\
18 \text { After }\end{array}$ & & & & $31(48)$ & $\begin{array}{l}12(19) \\
1 \text { Permanent }\end{array}$ & 0 \\
\hline Julkunen et al 1993 (19) & 26 Before & $\begin{array}{l}\text { II } \\
\text { III } \\
\text { IV } \\
\text { V } \\
\text { Unclassified }\end{array}$ & $\begin{array}{l}13 \\
9 \\
2 \\
1 \\
1\end{array}$ & $2(9)$ & $7(30)$ & 0 Permanent & 0 \\
\hline Our series & $\begin{array}{l}30 \text { Before } \\
2 \text { During }\end{array}$ & $\begin{array}{l}\text { II } \\
\text { III } \\
\text { IV } \\
\text { V } \\
\text { Glomerulo-s }\end{array}$ & $\begin{array}{l}3 \\
6 \\
14 \\
8 \\
\text { etosis }\end{array}$ & $5(16)$ & $4(13)$ & $1(3)$ & $1(3)$ \\
\hline
\end{tabular}

${ }^{\star} \mathrm{ND}=$ renal histological study not done.

$+\mathrm{R}=$ SLE in remission at pregnancy onset; $\mathrm{A}=$ active; $\mathrm{D}=$ SLE occurring during pregnancy or in the postpartum period.

differentiation between SLE flare and preeclampsia. We noted this situation in six cases and we considered that in two cases it was related to pre-eclampsia favoured by previous nephropathy or aPL, because extra-renal manifestations of SLE and anti-DNA antibodies were absent. Serum complement was normal in three of five cases. In the four other cases we considered that it was an SLE renal flare with hypocomplementaemia or extra-renal manifestations, or both. DNA antibodies were positive in all renal flares but absent in the flare with only arthralgias. An increased corticosteroid dose improved both complement level and proteinuria. Of note, planning pregnancy does not exclude the risk of pre-eclampsia. Previous reports have shown that the usefulness of serum complement levels is variable..$^{132324}$ Complement activation may be present in preeclampsia, but its intensity is lower than in SLE. $\mathrm{CH}_{50}$ usually remains within or just below normal values in pre-eclampsia and complement split products tend to be only moderately raised. The $\mathrm{CH}_{50} / \mathrm{Ba}$ ratio can be interesting, but measurement of $\mathrm{Ba}$ is not routinely practised. Wong et al did not find any difference in serum C3 or C4 levels whether or not patients relapsed during pregnancy. ${ }^{13}$ Nossent and Swaak observed that fewer than half of the pregnancies with decreased serum C3 levels were associated with a clinical SLE flare. ${ }^{16}$ On the contrary, Shibata et al and Rubbert et al noted that hypocomplementaemia correlated with poor pregnancy outcome. ${ }^{23} 24$ AntidsDNA levels were also correlated with SLE activity. ${ }^{26}$
In our series, one feto-maternal death due to sepsis occurred in a case of diffuse proliferative glomerulonephritis disclosing SLE. In our French register on SLE pregnancy, we observed another death in similar conditions. ${ }^{2}$ Several studies have shown that active SLE glomerulonephritis, especially diffuse proliferative, has the worse prognosis. In the series of Imbasciati et al, two of four women developed postpartum or postabortum acute anuria and died from sepsis. ${ }^{21}$ This mortality may justify a therapeutic abortion, which has been carried out in up to $18 \%$ of pregnancies in SLE nephritis (table 2), but was not performed in our series.

Proteinuria became significant in one third of our patients and renal function worsened in $3 \%$. Pre-eclampsia occurred in $16 \%$ of the pregnancies, more frequently when the pregnancy was unplanned, and led to rapid induced delivery, generally by caesarean section. No prolonged antihypertensive treatment was indicated. These renal anomalies were transient. Previous reports have shown a worsening of renal function in $11-27 \%$ of cases (table 3). This risk paralleled SLE activity: in the study of Hayslett and Lynn ${ }^{20}$ it was $10 \%$ when SLE was in remission at pregnancy onset, and it increased to $33 \%$ when SLE appeared during pregnancy. For SLE diagnosed before pregnancy, the risk of permanent renal deterioration seems low according to Oviasu et $a l^{18}$ and Julkunen et $a l,{ }^{19}$ but it should be noted that the latter included few cases of diffuse proliferative glomerulonephritis (table 3 ). 
FETAL PROGNOSIS

We observed a live birth rate of $75 \%$. Previous reports have shown live birth rates ranging between 58 and $84 \%$ (table 2). However, the number of cases studied, the selection of data-including or not pregnancies occurring in active SLE, or SLE developing in the postpartum period, and the differential use of therapeutic abortions make comparisons difficult. In our series, after exclusion of embryonic losses, fetal survival rate in planned pregnancies was $92 \%$, which is close to that observed in the French population and our global population of SLE planned pregnancies. ${ }^{3}$ In the series of Julkunen et al, including only inactive SLE at pregnancy onset, the live birth rate was $95.6 \%$, but two therapeutic abortions had been performed. ${ }^{19}$ In the study of Hayslett and Lynn, 31 pregnancies occurred in women with inactive SLE, with seven therapeutic and three spontaneous abortions. ${ }^{20}$ In the series of Jungers et al, all pregnancies occurring in women with inactive SLE ended in live births, but this concerned only 11 pregnancies. ${ }^{22}$ Oviasu et al, including only women with inactive SLE, observed eight spontaneous abortions and one stillbirth among 47 pregnancies in SLE with previous nephritis. ${ }^{18}$ In these three studies the abortion date was not precisely known.

In our series, no criterion appeared to be a statistically significant indicator for fetal survival. SLE activity, hypertension, and the presence of APS were not indicators, but few patients had either of these manifestations. Major indicators of fetal outcome emerging in a series studying pregnancy outcome in SLE nephritis were SLE activity at pregnancy onset, ${ }^{202}$ severity of maternal renal disease, ${ }^{21} 27$ the presence of hypertension ${ }^{27}$ or lupus anticoagulant, ${ }^{28}$ even if these criteria did not reach statistical significance in all series. Active renal disease was also a predictor of fetal loss. ${ }^{21} 27$

In conclusion, pregnancy need not be discouraged in women with SLE nephritis with normal or mildly impaired renal function. Deterioration of renal function rarely occurs when serum creatinine is below $100 \mu \mathrm{mol} / 1$. However, these pregnancies are at high risk of pre-eclampsia and prematurity.

1 Urowitz MB, Gladman DD, Farewell VT, Stewart J, McDonald J. Lupus and pregnancy studies. Arthritis Rheum 1993;36:1392-7.

2 Lê Thi Huong D, Wechsler B, Piette JC, Blétry O, Godeau P. Pregnancy and its outcome in systemic lupus erythemaP. Pregnancy and its outcome in
tosus. Q J Med 1994;87:721-9.

3 Lê Thi Huong D, Wechsler B, Vauthier-Brouzes D, Seebacher J, Blétry O, Darbois Y, et al. Outcome of planned pregnancies in systemic lupus erythematosus. A prospecpregnancies in systemic lupus erythematosus. A prospec-
tive study of 62 pregnancies. Br J Rheumatol 1997;36: tive study

4 Abu-Shakra M, Urowitz MB, Gladman DD, Gough J. Mortality studies in systemic lupus erythematosus. Results from a single center. II. Predictor variables for mortality. J Rheumatol 1995;22:1265-70

5 Lê Thi Huong D, Papo T, Beaufils H, Wechsler B, Blétry O, Baumelou A, et al. Renal involvement in systemic lupus erythematosus. A study of 180 patients from a single center. Medicine (Baltimore) 1999;78:148-66.

6 Hochberg MC. Updating the American College of Rheumatology revised criteria for the classification of systemic lupus erythematosus. Arthritis Rheum 1997;40:1725-34.

7 Wilson WA, Gharavi AE, Koike T, Lockshin MD, Branch DW, Piette JC, et al. International consensus statement on preliminary classification criteria for definite antiphospholipid syndrome. Arthritis Rheum 1999;42:1309-11.

8 Churg J, Bernstein J, Glassock RJ. Lupus nephritis. In: Churg J, Bernstein J, Glassock RJ, eds. Renal diseases. Classification and atlas of glomerular diseases. New York: Igaku Shoin, 1995:151.

9 Branch DW. Thoughts on the mechanism of pregnancy loss associated with the antiphospholipid syndrome. Lupus 1994;3:275-80

10 Boumpas DT, Austin HA, Vaughn EM, Yarboro CH, Klippel JH, Balow JE. Risk for sustained amenorrhea in patients with systemic lupus erythematosus receiving intermittent pulse cyclophosphamide therapy. Ann Intern Med 1993; 119:366-9.

11 Fine LG, Barnett EV, Danovitch GM, Nissenson AR, Conolly ME, Lieb SM, et al. Systemic lupus erythematosus in pregnancy. Ann Intern Med 1981;94:667-77.

12 Mok CC, Lau CS, Woon Sing Wong R. Risk factors for ovarian failure in patients with systemic lupus erythematosus receiving cyclophosphamide therapy. Arthritis Rheum $1998 ; 41: 831-7$

13 Wong KL, Chan FY, Lee CP. Outcome of pregnancy in patients with systemic lupus erythematosus. A prospective study. Arch Intern Med 1991;151:269-73.

14 Petri M, Howard D, Repke J. Frequency of lupus flare in pregnancy. The Hopkins Lupus Pregnancy Center experience. Arthritis Rheum 1991;34:1538-45.

15 Mintz G, Niz J, Guttierez G, Garcia-Alonso A, Karchmer S. Prospective study of pregnancy in systemic lupus erythematosus: results of a multidisciplinary approach. J Rheumatol 1986;13:732-9.

16 Nossent HC, Swaak TJG. Systemic lupus erythematosus. VI. Analysis of the interrelationship with pregnancy. J Rheumatol 1990;17:771-6.

17 Ruiz-Irastorza G, Lima F, Alves J, Khamashta MA, Simpson $\mathrm{J}$, Hughes GRV, et al. Increased rate of lupus flare during pregnancy and the puerperium: a prospective study of 78 pregnancies. Br J Rheumatol 1996;35:133-8.

18 Oviasu E, Hicks J, Cameron JS. The outcome of pregnancy in women with lupus nephritis. Lupus 1991;1:19-25.

19 Julkunen H, Kaaja R, Palosuo T, Grbnhagen-Riska C, Teramo K. Pregnancy in lupus nephropathy. Acta Obstet Gynecol Scand 1993;72:258-63.

20 Hayslett JP, Lynn RI. Effect of pregnancy in patients with lupus nephropathy. Kidney Int 1980;18:207-20.

21 Imbasciati E, Surian M, Bottino S, Cosci P, Colussi G, Ambrososo GC, et al. Lupus nephropathy and pregnancy. Nephron 1984;36:46-51.

22 Jungers P, Dougados M, Pelissier C, Kuttenn F, Tron F, Lesavre $\mathrm{Ph}$, et al. Lupus nephropathy and pregnancy: report of 104 cases in 36 patients. Arch Intern Med 1982; 142:771-6.

23 Shibata S, Sasaki T, Hirabayashi Y, Seino J, Okamura K, Yoshinaga $\mathrm{K}$, et al. Risk factors in the pregnancy of patients with systemic lupus erythematosus: association of hypocomplementaemia with poor prognosis. Ann Rheum Dis 1992;51:619-23

24 Rubbert A, Pirner K, Wildt L, Kalden JR, Manger B. Pregnancy course and complications in patients with systemic lupus erythematosus. Am J Reprod Immunol 1992;28: $205-7$.

25 Abramson SB, Buyon JP. Activation of the complement pathway: comparison of normal pregnancy, preeclampsia and systemic lupus erythematosus during pregnancy. Am J Reprod Immunol 1992:28:183-7.

26 Tomer Y, Viegas OAC, Swissa M, Koh SCL, Shoenfeld Y. Levels of lupus autoantibodies in pregnant SLE patients: correlations with disease activity and pregnancy outcome. Clin Exp Rheumatol 1996;14:275-80.

27 Rahman P, Gladman DD, Urowitz MB. Clinical predictors of fetal outcome in systemic lupus erythematosus. J Rheumatol 1998;25:1526-30.

28 Packham DK, Lam SS, Nicholls K, Fairley KF, KincaidSmith PS. Lupus nephritis and pregnancy. Q J Med 1992; 300:315-24. 